\title{
Controlled fluoridation of amorphous carbon films deposited at reactive plasma conditions
}

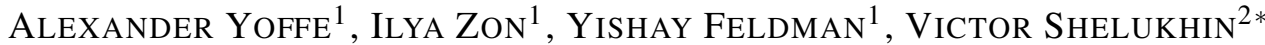 \\ ${ }^{1}$ Weizmann Institute of Science, Rehovot, Israel \\ ${ }^{2}$ Tel Aviv University, Tel Aviv, Israel
}

\begin{abstract}
A study of the correlations between plasma parameters, gas ratios, and deposited amorphous carbon film properties is presented. The injection of a $\mathrm{C}_{4} \mathrm{~F}_{8} / \mathrm{Ar} / \mathrm{N}_{2}$ mixture of gases was successfully used in an inductively coupled plasma system for the preparation of amorphous carbon films with different fluoride doping at room-temperature, using silicon as a substrate. This coating was formed at low-pressure and low-energy using an inductively coupled plasma process. A strong dependence between the ratios of gases during deposition and the composition of the substrate compounds was shown. The values of ratios between $\mathrm{Ar}$ (or $\mathrm{Ar}+\mathrm{N}_{2}$ ) and $\mathrm{C}_{4} \mathrm{~F}_{8}-1: 1$ and between $\mathrm{N}_{2}$ and $\mathrm{Ar}-1: 2$ in the $\mathrm{N}_{2} / \mathrm{Ar} / \mathrm{C}_{4} \mathrm{~F}_{8}$ mixture were found as the best for low fluoridated coatings. In addition, an example of improving the etch-passivation in the Bosch procedure was described. Scanning electron microscopy with energy dispersive spectroscopy options, X-ray diffraction, and X-ray reflectivity were used for quantitative analysis of the deposited films.
\end{abstract}

Keywords: carbon deposition; reactive plasma; fluoridation

(C) Wroclaw University of Technology.

\section{Introduction}

Carbon is one of the most widely studied elements. Amorphous carbon (a-C) is a noncrystalline form of carbon that has only a short range structural order. A variety of forms of a-C can be deposited [1]. For example, a-C films can exhibit diamond-like properties [2]. There are many applications of the films due to their excellent mechanical properties, infrared transparency, and mostly transparency to visible radiation along with a tunable refractive index (1.36 to 2.81). Some of their applications are listed below:

1. Corrosion resistant coatings for magnetic storage media $[1,3]$;

2. Low-friction scratch-resistant coatings for polycarbonate sunglasses, razor blades, machining tools, and automotive components $[1,3,4]$;

\footnotetext{
*E-mail: Victor.Shelukhin@gmail.com
}

3. Coatings to protect biological objects, such as artificial heart valves and joint implants [1, 5-7];

4. Anti-reflection coatings for $\mathrm{Si}$ solar cells [8-10].

Fluoridated a-C films (a-C/F) have slightly different properties [11, 12], and can be used for most of the above purposes as well as an insulating dielectric layer between other films [12].

A variety of methods have been used to deposit a-C thin films. Graphite, like carbon, is usually produced by sputtering of a graphite target, while tetrahedral amorphous carbon is deposited using vacuum arc deposition or pulsed-laser deposition. The polymer-like-carbon and the hydrogen containing diamond-like-carbon are formed by using either sputtering or plasma-enhanced chemical vapor deposition (PECVD) [1, 12-15]. The a-C/F is produced by PECVD [12] using a hot-wire chemical vapor deposition [16], or, if we are dealing with pure carbon film modification, surface fluoridation is used [17]. 
In this paper we study the effect of $\mathrm{C}_{4} \mathrm{~F}_{8} / \mathrm{Ar}$, $\mathrm{C}_{4} \mathrm{~F}_{8} / \mathrm{N}_{2}$ gas mixtures on the quality of the a-C layers for different levels of fluoridation.

We present a new use of an inductively coupled plasma (ICP) system for making a-C films with a widely controlled value of fluoridation. We believe that this method of a-C film production is simpler than the methods described earlier. During processing in the ICP system, the high density, low-pressure and low-energy inductively coupled plasma is produced. The ability to change the plasma parameters by changing gas flow and gas mixtures enables us to create a-C films with different ratios between carbon and fluoride.

\section{Experimental}

The setup used for the a-C/F deposition was an ICP system, developed by SPTS Technologies, which is presented schematically in Fig. 1. This system is equipped with an RF generator source (13.56 MHz, $1.5 \mathrm{~kW}$ ) and a stage RF generator $(13.56 \mathrm{MHz}, 300 \mathrm{~W})$. The gases, which are supplied to the system through the gas inlet, have a purity of $99.999 \%$. The wafer for carbon layer deposition is placed on the helium cooled electrode for temperature control.

The quality of the process is limited by the stability of the plasma. We made the coatings on the 2 and 5 inch silicon wafers with 2 to $5 \mathrm{~nm}$ native oxide layers, without any special preparation besides cleaning.

The TTRAX III (Rigaku, Japan) was used for $\mathrm{X}$-ray diffraction (XRD) analyses and X-ray reflectivity (XRR) experiments.

The films surfaces were investigated using a scanning electron microscope Supra 55VP FEG LEO (SEM) with an energy dispersive spectroscopy (EDS) probe. The optical properties were studied by ellipsometry (a manual ellipsometer Rudolph, wavelength $634.2 \mathrm{~nm}$ ).

\section{Results}

The examined parameters included ICP power, base pressure, temperature, gas flow rate, gases

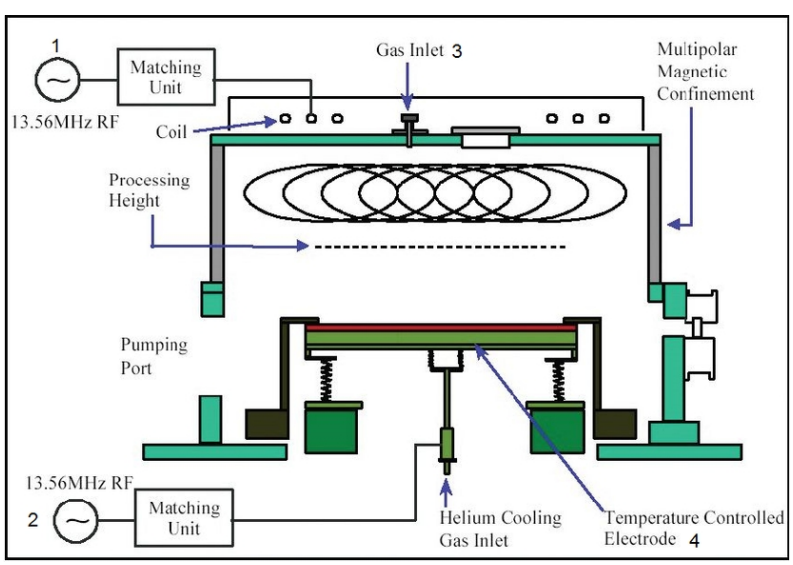

Fig. 1. Inductively coupled plasma setup scheme, $1-$ $\mathrm{RF}$ generator source $1.5 \mathrm{~kW}, 2-\mathrm{RF}$ generator $300 \mathrm{~W}, 3$ - gas inlet, 4 - helium cooled temperature controlled electrode.

present and their ratios. The complete study of these parameters influence on the prepared films was done and the best conditions were selected. The test powers applied to the coil and to the plate films with minimal fluoridation levels were achieved under the following conditions: (i) the ICP source RF generator power: $200 \mathrm{~W}$; (ii) the power on the stage RF generator: $20 \mathrm{~W}$; (iii) gas flow, (which was varied from 5 to $100 \mathrm{sccm}$ ), 5 to $10 \mathrm{sccm}$ for each gas; (iv) the working pressure: $4 \mathrm{~Pa}$. We found that the higher the gas flow or the higher the plasma density, the higher the fluoridation ( $\mathrm{C} / \mathrm{F}$ ratio increased up to $1: 1)$. A typical deposition rate was in the range of 15 to $20 \mathrm{~nm} / \mathrm{min}$. Direct measurements, using irreversible "Spirig" thermometers, showed that the temperature did not increase above $50{ }^{\circ} \mathrm{C}$, and it can be assumed that the rise in temperature not exceeding $50{ }^{\circ} \mathrm{C}$ would not influence the deposition process.

The gas ratio in the gas mixture was found to be the most important parameter that had an impact on plasma properties. In Fig. 2 the effect of the gas mixtures upon the $\mathrm{C} / \mathrm{F}$ ratio in the deposited layer is shown.

Our results show that the presence of $\mathrm{Ar}$ and $\mathrm{N}_{2}$ is very crucial for achieving a high ratio of $\mathrm{C} / \mathrm{F}$. The highest $\mathrm{C} / \mathrm{F}$ ratio is obtained when the ratio between $\mathrm{N}_{2}: \mathrm{Ar} \mathrm{C}_{4} \mathrm{~F}_{8}$ is 1:2:3. ( $\mathrm{N} 2+\mathrm{Ar} \mathrm{C}_{4} \mathrm{~F}_{8}=1: 1$, 
$\mathrm{N} 2: \mathrm{Ar}=1: 2$ ). In addition, it is found that the presence of $\mathrm{O}_{2}$ in the gas mixture has only a negative influence on the film growth. The examination of the mixtures of $\mathrm{N}_{2}, \mathrm{Ar}, \mathrm{C}_{4} \mathrm{~F}_{8}$ and $\mathrm{O}_{2}$ gases for the fluoridated a-C film preparation was done in the full range of the gases contents, but the study of the possibility of other gases usage will be done in the future.

The composition of deposited layers was checked by EDS for all prepared samples in different regions (from the center to the edge of the wafer) to exclude mistakes due to non-uniform deposition (the difference in the thickness between the center and the edge of the wafers was about 5 to $15 \%$ ). All samples exhibited C, F and Si presence in the EDS spectra. Si presence (signal from wafer) in the EDS spectra varied from $30 \%$ to $85 \%$. A lower content of $\mathrm{Si}(30 \%)$ was found when a thick layer, of about 400 to $500 \mathrm{~nm}$, was deposited (15 to $30 \mathrm{~min}$. deposition time, depending on power and flow conditions). This relation between $\mathrm{C}$ and $\mathrm{F}$ corresponds to the ratio of the atomic concentrations.

When a thin layer, of about 100 to $200 \mathrm{~nm}$, was deposited (5 to $10 \mathrm{~min}$. deposition time), the Si content rose to $85 \%$. The data from the EDS spectra were recalculated to exclude mistakes due to the influence of Si peaks arising from the substrate on $\mathrm{C}$ and $\mathrm{F}$ peaks maximum values and on the $\mathrm{C} / \mathrm{F}$ ratio, respectively. Differences in the measured values of the samples which were prepared separately under equal plasma conditions did not exceed $12 \%$. Amorphism of the deposited layers was checked by XRD, Fig. 3.

Using GlobalFit Reflectivity analysis software (Rigaku, Japan) the density, thickness and roughness of surface (arithmetical mean roughness, $\mathrm{Ra}$ ) were evaluated for all films by the Parratt algorithm with R-factor better than $2 \%$. Typical experimental (red) and calculated (blue) profiles are plotted in Fig. 4 and the evaluated parameters are given in Table 1 . The results of mathematical calculations presented in the Table 1 were rounded to two decimal places. We obtained for the a-C layer: a density of $\sim 2.0 \mathrm{~g} / \mathrm{sm}^{3}$, and a roughness of $\sim 0.6 \mathrm{~nm}$. A density of $\sim 2.0 \mathrm{~g} / \mathrm{sm}^{3}$ is lower than the tabulated value for the density of carbon [18], but it does correspond with the data for amorphous carbon films [15]. The roughness is about an atomic layer in thickness, and it looks like the samples are of the highest possible quality that is technically possible to produce. The $\mathrm{Ra}$ of an order of an atomic layer was found for all the samples prepared by ICP; it means that the roughness is not a function of gas composition, but the process characteristics.

The thicknesses evaluated from the more reliable XRR process (given in Table 1 for one of the samples), correspond to the thicknesses calculated from ellipsometry data (which show the refractive index in the range of 1.81 to 2.41 ), with an accuracy of $3 \%$.

\section{Discussion}

We suggest the following scenario that can explain the obtained results. The presence of $\mathrm{Ar}$ leads to decomposition of $\mathrm{C}_{4} \mathrm{~F}_{8}$ [19]; the suitable pressure-energy conditions and $\mathrm{N}_{2}$ presence allow the $\mathrm{C}$ atoms to reach the surface, since a substantial amount of $\mathrm{F}$ atoms are removed from the vacuum chamber. The selection of the pressure-energy conditions and selection of gas flow allows the control of the fluoridation level.

Generally, during etching processes, materials, such as $\mathrm{CHF}_{3}, \mathrm{C}_{2} \mathrm{~F}_{6}$ and $\mathrm{C}_{4} \mathrm{~F}_{8}$ (in our case), are used for passivation and act as the inhibitors due to their high tendencies to polymer forming. $\mathrm{C}_{4} \mathrm{~F}_{8}$ plasma produces neutral $\mathrm{CF}_{x}$ radicals and stable molecules (such as $\mathrm{C}_{2} \mathrm{~F}_{4}$ ). The presence of $\mathrm{Ar}$ in the plasma leads to the enhanced ionization and to the dissociation of $\mathrm{C}_{4} \mathrm{~F}_{8}$. Ar atoms do not participate in chemical reactions, but the presence of these atoms leads to decomposition of $\mathrm{C}_{4} \mathrm{~F}_{8}[19,20]$. The addition of $\mathrm{Ar}$ to $\mathrm{C}_{4} \mathrm{~F}_{8}$ results in an increase of the plasma density relative to that of pure $\mathrm{C}_{4} \mathrm{~F}_{8}$. This leads to pumping out of increased amounts of fluorine, thus, a reduction of the fluorine content. Furthermore, not only both neutral flux density and positive ion density increase but the ratio of ion/neutral density is increased, as well. As a result of these processes we observed different reductions of the fluorine content in the 

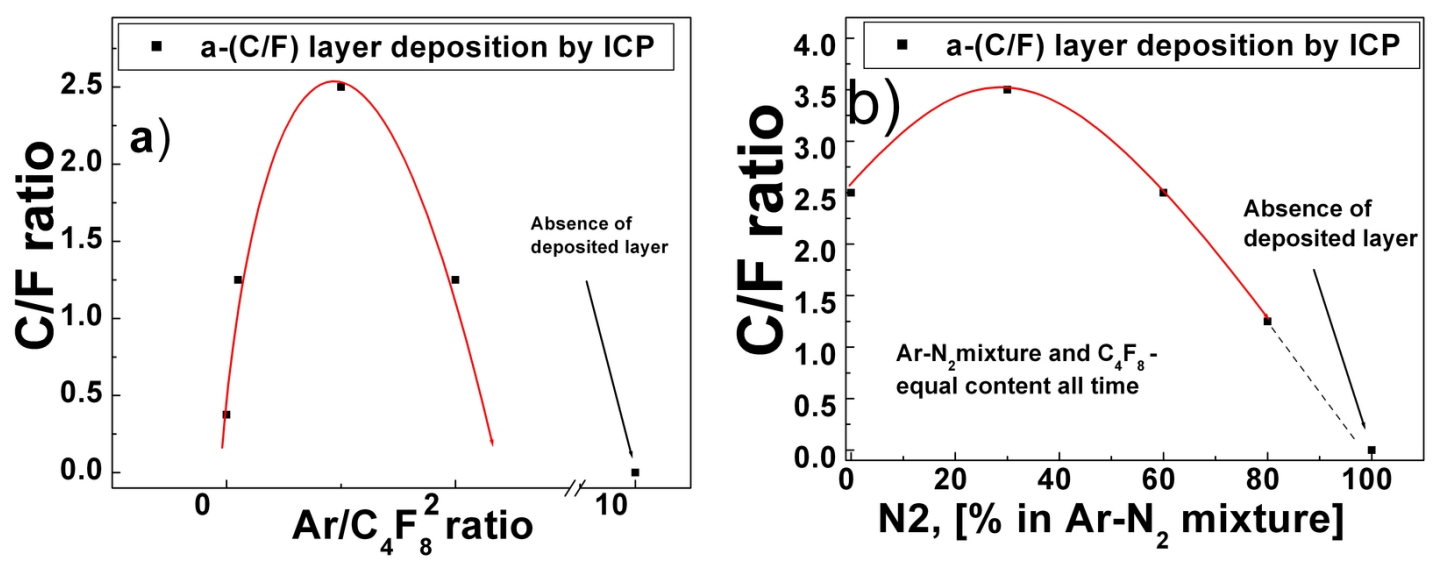

Fig. 2. The influence of the gas ratios (ratio of the gases introduced into the chamber during the plasma process) on the fluoridation of a-C layers. Every point shown is the average value from 3 or 4 experiments. In red fitting the data points to an assumed curve. The point $\mathrm{N} 2[\%]=0$ in $2 \mathrm{~b}$ corresponds to the point $\mathrm{Ar} / \mathrm{C}_{4} \mathrm{~F}_{8}=$ 1 in $2 \mathrm{a}$.

Table 1. The film parameters evaluated from the calculation results of XRR data for a-C film made under best conditions, $\left(\mathrm{N} 2+\mathrm{Ar}: \mathrm{C}_{4} \mathrm{~F}_{8}=1: 1, \mathrm{~N} 2: \mathrm{Ar}=1: 2\right)$.

\begin{tabular}{|c|c|c|c|c|c|}
\hline Layer number & Material & Thickness (nm) & Density $\left(\mathrm{g} / \mathrm{cm}^{3}\right)$ & Roughness (nm) & Comment \\
\hline 1 & "Carbon" & 82.43 & 2.00 & $0.54 *$ & calculation \\
\hline 2 & $" \mathrm{SiO}_{2} "$ & 3.83 & 2.34 & & calculation \\
\hline 3 & "Si" & & 2.33 & $0.01 * *$ & substrate \\
\hline
\end{tabular}

*Physical meaning - The roughness is of the order of an atomic layer thickness,

**Physical meaning - The roughness is below an atomic layer thickness.

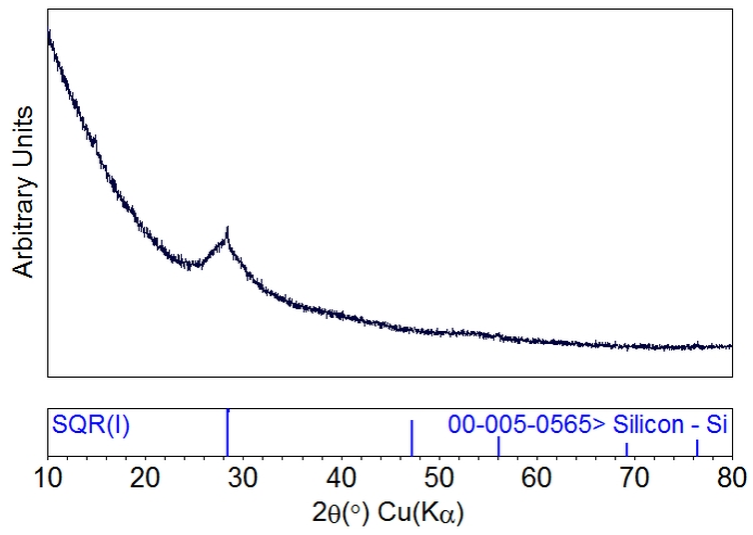

Fig. 3. XRD pattern of amorphous carbon film.

fluorocarbon layer when different amounts of $\mathrm{Ar}$ were added to $\mathrm{C}_{4} \mathrm{~F}_{8}$.

As was shown above, the presence of $\mathrm{N}_{2}$ influenced the film fluoridation during the process.

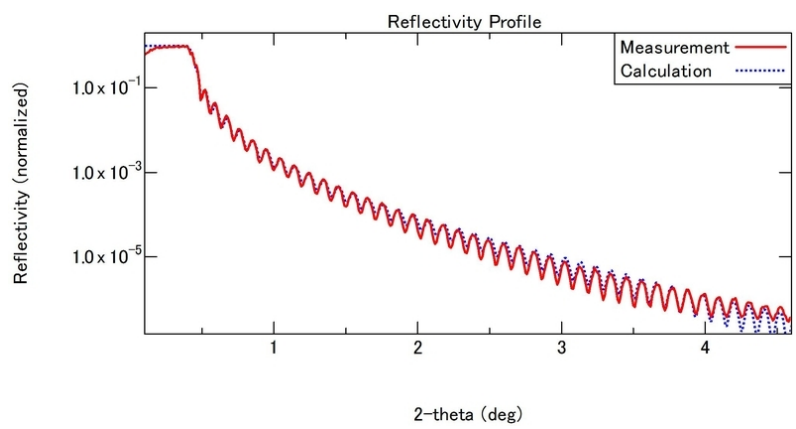

Fig. 4. Typical XRR raw data (red) from the TTRAX III detector and calculation curve (blue, dotted) formatted by the "Global Fit" program.

This effect was previously mentioned in [21]. It has been postulated that $\mathrm{N}_{2}$ acts to reduce polymerization and promotes free fluorine in the plasma by combining with fluorocarbon etchants to 
produce by-products, containing $\mathrm{C}$ and $\mathrm{N}$. This reaction would result in free fluorine being released into the plasma. The ions, which are directed towards the sample, 'carry' the carbon onto the sample.

We emphasize that the structural properties of the films (amorphism) have been confirmed and they correspond to the properties of films made by other methods. The optical properties were studied by ellipsometry, which confirmed the amorphous character of the film and revealed the refractive index of about 2.41 for the film with lower fluoridation ( $\mathrm{C} / \mathrm{F} \sim 3.5)$, while for the films with high $\mathrm{F}$ content $(\mathrm{C} / \mathrm{F} \sim 1)$ the refractive index decreased to 1.81. The accuracy of calculation from ellipsometry data was about $2 \%$ and the calculated a-C refractive index was close to reported value [22]. It shows that our films can be used as the films prepared by different methods for coatings, where the optical properties are important either. The options to prepare the films with controlled refractive index looks interesting but the complete investigation of optical properties of the prepared films is out of range of this paper and it can be addressed by future studies.

\section{Applications}

The ICP process with $\mathrm{C}_{4} \mathrm{~F}_{8}$ gas has been used for deposition of carbon-fluoride compounds in the Teflon- $\left(\mathrm{C}_{2} \mathrm{~F}_{4}\right)_{\mathrm{n}}$-form for etching (fundamental aspects of the plasma-assisted etching process have been described in [23]) and for vertical $\mathrm{Si}$ etching-passivation process called the Bosch procedure [24].

Our results show that this method could be used for deposition of a-C film with a low fluoride content. It was found, in addition to the main aim, i.e. differently fluoridated carbon a-C coatings, that our processing in the $\mathrm{Ar} / \mathrm{C}_{4} \mathrm{~F}_{8}$ gas mixture significantly improved the etch-passivation Bosch procedure, mentioned above. As can be seen from comparing Fig. 5a with Fig. 5b, the roughness of the walls ('scallops') of the etched $\mathrm{Si}$ wells is 3 to 5 times less in the case when the $\mathrm{Ar} / \mathrm{C}_{4} \mathrm{~F}_{8}$ gas mixture was used instead of pure $\mathrm{C}_{4} \mathrm{~F}_{8}$. Typical timing of one process cycle was $10 \mathrm{~s}$ etching and $10 \mathrm{~s}$ passivation (ICP source RF generator power was $500 \mathrm{~W}$ for both processes, etching and passivation; the power on the stage RF generator was $100 \mathrm{~W}$ ), the whole process time corresponded to the needed etched well depth.

The profile of the etched features on the walls after processing in the $\mathrm{Ar} / \mathrm{C}_{4} \mathrm{~F}_{8}$ gas mixture was much smoother. This result could be applied to the technical process of vertical silicon etching [25].

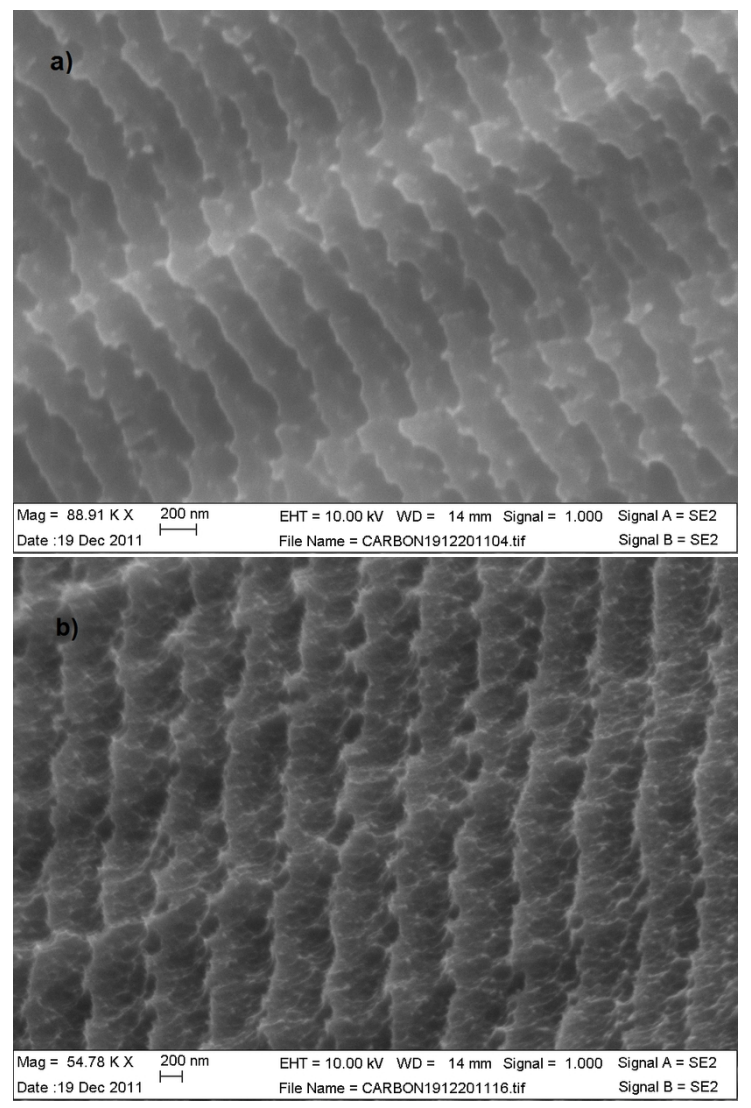

Fig. 5. SEM images of the walls of the wells etched in Si using the Bosch procedure without Ar (a), the 'scallops' are characterized by a height of about $\sim 200 \mathrm{~nm}$. In the process with Ar (b), the "scallops" are smooth with a height of $\sim 50 \mathrm{~nm}$.

\section{Conclusions}

- A simple, low cost method of a-C/F films preparation using ICP, and particular gas mixture parameters employed in the process were presented. The influence of ICP 
parameters on the properties of films was explained.

- The film quality was good (amorphous phase, reproducible film properties under the same preparation conditions, very good roughness, etc.).

- Different fluoridation levels of the a-C films were obtained, what can be used for different technical applications, similar to a-C films prepared by different methods.

- XRR data analyses were successfully performed for the characterization of the a-C thin films on the oxidized Si substrate.

- An improvement of the Bosch procedure was demonstrated.

\section{Acknowledgements}

We thank Prof. Igor Lubomirsky and Dr. Ora Bitton for fruitful discussions at the initial stage of this research. Special thanks go to Huma Ashraf, the representative of SPTS Technologies, for helpful comments during the preparation of this article.

\section{References}

[1] Silva S.R.P., Properties of Amorphous Carbon, INSPEC, London, 2003.

[2] Aisenberg S., Chabot R., J. Appl. Phys., 42 (7) (1971), 2953.

[3] Grill A., Diam. Relat. Mater., 8 (1999), 428.

[4] Kimock F.M., Knapp B.J., Surf. Coat. Tech., 56 (1993), 273.

[5] Yang Y., Franzen S., Olin C., Cells Mater, 6 (4) (1996), 339.

[6] Mclaughlin J.A., Meenan B., Maquire P., JAMIESON N., Diam. Relat. Mater., 5 (3 - 5) (1996), 486.

[7] Du C., Su X.W., Cui F.Z., ZHU X.D., Biomaterials, $19(7-9)(1998), 651$.

[8] Alaluf M., Appelbaum J., Klibanov L., Brinker D., SCheiman D., Croitoru N., Thin Solid Films, $256(1-2)$ (1995), 1.
[9] Klyui N.I., Litovchenko V.G., Rozhin A.G. Dikusha V.N., Kittler M., Seifert W., Sol. Energ. Mat. Sol. C., $72(1-4)$ (2002), 597.

[10] Moravec T.J., LeE J.C., J. Vac. Sci. Technol., 20 (3) (1982), 338.

[11] Yao Z.Q., Yang P., Huang N., Sun H., Wang J., Appl. Surf. Sci., $230(1-4)(2004), 172$.

[12] Biswas N., Harris H. R., Wang X., Celebi G., Temkin H., Gangopadhyaya S., J. Appl. Phys., 89 (8) (2001), 4417.

[13] Robertson J., Mat. Sci. Eng. R., 37 (2002), 129.

[14] Friedmann T.A., Sullivan J.P., KnapP J.A., Tallant D.R., Follstaedt D.M., Medlin D.L., Mirkarimi P.B., Appl. Phys. Lett., 71 (26) (1997), 3820.

[15] Clarke G.A., Xie Y., Eldridge J.E., Parsons R.R., Thin Solid Films, 280 (1996), 130.

[16] LAU K.K.S., Pryce Lewis H.G., Limb S.J., KWAN M.C., Gleason K.K., Thin Solid Films, 395 (2001), 288.

[17] Kim J., Shojiro M., Masahito B., J. Surf. Finish. Soc. Jpn., 53 (12) (2002), 933.

[18] http://education.jlab.org/itselemental/ ele006.html.

[19] Masaya I., Surf. Coat. Tech., 158 (59) (2002), 377.

[20] Li X., Ling L., Hua X., Fukasawa M. , Oehrlein G.S., Barela M., Anderson H.M., J. Vac. Sci. Technol. A, 21 (1) (2003), 284.

[21] Hua X., Wang X., Fuentevilla D., Oehrlein G.S., Celit F.G., Kirmse K.H.R., J. Vac. Sci. Technol., 21 (5) (2003), 1708.

[22] http://refractiveindex.info/?group= CRYSTALS $\{\&\}$ material $=C$.

[23] MAYER T.M., BARKeR R.A., J. Vac. Sci. Technol., 21 (3) (1982), 757.

[24] US Patent 6531068, (2012), http://www. freepatentsonline.com/6531068.html.

[25] Kendall D.L., Annu. Rev. Mater. Sci., 9 (1979), 373. 